\title{
Geoffrey C. Bowker, Stefan Timmermans, Adele E. Clarke, \& Ellen Balka (eds) (2015) Boundary Objects and Beyond. Working with Leigh Star. Cambridge MA, London: MIT Press. 548 pages. ISBN: 978-0-262-02974-2
}

\author{
Attila Bruni \\ attila.bruni@unitn.it
}

I knew when I agreed to review this text that it would be a challenge. Leigh Star (although for some she was Susan, as recalled by John Leslie King - chapter 17) was one of the most influential scholars of science and technology studies of the past thirty years, and her contribution has marked (and still inspires) an entire field of research. Moreover, she was renowned for the calmness and serenity that she conveyed, the poems that she inserted in her writings and speeches, and the almost whispered - but incisive - tone of voice with which she used to speak. That is to say, it is almost impossible to speak of Leigh Star's work without speaking of Leigh herself. Hence reviewing the book that originates from the conference held in her honour at the University of California, San Francisco, in September 2011 carries the serious risk of producing nothing more than an apologia for her work and her person. To avoid this risk, therefore, I promise myself and the reader not to address Leigh Star's research in this review, even less to describe her personality, but instead to concentrate entirely on the book.

From a purely material point of view, the book is big, heavy and it has a somehow unusual page format which makes it larger than the 'normal' books you have in your library. The text (articulated in four sections: Ecologies of Knowledge; Boundary Objects; Marginalities and Suffering; Infrastructure) consists of collection of writings by Star accompanied by contributions from coauthors/colleagues/friends (the three catego- ries often overlap). The contributions are often outright research papers which reflect on Star's concepts and approach, or which show the efficacy and practical relevance of her thought in light of various research examples. Others are instead more narrative in form, as in the case of the 'epistolary' text in which Brian Cantwell Smith (chapter 9) draws on the concept of boundary object to extend the discussion to what counts as an object, and what is implied ontologically by looking at the world in terms of objects. Or in the case of Eevi Beck, who presents a patchwork of different texts and rhetoric styles in order to thematize "vague areas of science; where the solidity of theories seems to peter out; where scientists emerge as eminently human in our splendor and our fallibility" (chapter 22: 436). Or in the case of Nina Wakeford (chapter 3), who discusses Leigh's queerness by considering a working paper written by Star for a feminist conference at Aarhus University in 1994. Wakeford then illustrates the making of a four-minute digital video (for the conference in Leigh's honor) and reflects on how to challenge and innovate the methodological repertoire of STS.

The complete version of Star's paper appears some chapters later (chapter 6). As I read it (I had never heard mention of it before), I was reminded of my reactions on first reading Star on the occasion of my degree thesis, when I stumbled upon the famous 'onion paper'. Magnificent, I thought. Incomparable, splendid, as well as 
other adjectives indicating beauty or exceeding all expectations. In this paper Leigh transports the reader to the San Francisco of the 1970s and the do-it-yourself technologies and practices for artificial insemination in the lesbian community. She then addresses the question of feminism as a method, and of methodology as an experiential (and political) form of ordering practice. I shall not go into details on the chapter so as not to deprive readers of the pleasure and surprise that reading it evokes, but I confess that I bit my lip on reading that "the trajectory of learning becomes a series of encounters with the objects of practice in the community" (chapter 6: 154); a reflection which I thought constituted the original feature of a paper of mine published in 2001 (sic!).

In fact, on reading the entire book one gains the distinct impression that Leigh Star anticipated the main themes that animate the current debate not only in STS, but more generally in the social sciences. I think three examples are sufficient.

The first is the attention paid to the role played by classifications and infrastructures in the contemporary world, and to the idea itself of infrastructure as a relational concept. For example, if we consider the programme of the last 4S/EASST conference, we find that the word 'infrastructure' is one of the most recurrent (to be exact, it appears in the titles of 61 papers, and in the names of 6 different tracks); this year $4 \mathrm{~S}$ has established an 'STS Infrastructure Award'; and if we review the last five years of the main STS journals (such as Science, Technology and Human Values, Science and Technology Studies, and Science, Technology and Society), the theme of infrastructure is ubiquitous. If we then move from STS journals to more generalist ones (such as Theory, Culture and Society, or Sociology), the result does not change: indeed, the numbers increase. Although these are mere numerical indicators (and Star's research demonstrates how many different forms of reductionism and standardization lie concealed behind numbers), I believe that it can be argued that the theme of infrastructure is today of key importance for those who deal with STS and/or try to read the 'social' through an STS lens (not by chance, this same book is part of the MIT 'Infrastructures Series'). Of course, this also applies to the attention devoted to infrastructure by diverse STS scholars (first of all, Geoffrey Bowker); but also in this case I feel sufficiently confident in stating that "Steps toward an ecology of infrastructure: design and access for large information spaces" and "The ethnography of infrastructure" (both in the text) are seminal articles for anyone dealing with this issue.

The second theme is instead linked to the relationship between the visible and invisible, and in particular, to the articulation work that makes it possible to hold together the two poles of what (like so many other oppositions and clashes) should be conceived as a continuum rather than a dichotomy. This is the issue that more than any other ties Star's approach to symbolic interactionism and makes social practice the prime unit of analysis with which to determine what people actually do when they work; as well as how much and what type of work people must perform 'covertly' before they can devote themselves to 'real-and-proper' work. In other words, what activities count as 'work' and what activities (or actors) are instead removed.

In/visible work has been a core theme for diverse bodies of inquiry (CSCW, $\mathrm{HCl}$, organization studies, among others), becoming a concept almost taken for granted in contemporary STS. This has led to a paradoxical consequence and to a further variant of invisible work, which Star and Strauss mention only in passing, but which Kjeld Schmidt well evidences in his contribution (chapter 18: 346): "the elimination of work from the agenda of respectable intellectual interests". Again, I think it suffices to look at the programme of the last 4S/EASST conference to grasp the importance assumed by the theme of work in contemporary STS: of the 185 tracks on the conference programme, not even one centres specifically on the work/organization dynamics that characterize technoscientific contexts. And also when considering the titles of the individual papers, the word 'work' appears much more often as an item comprised in other words (primarily 'network' and 'framework'), not as a word in its own right. As a researcher interested in action of technologies in organizational contexts, I cannot but endorse the exhortation with which Schmidt closes his chapter (18: 349): "a fine way to honor Leigh's work would be to strive to make work - 
the skilful work practices and the problems and concerns of ordinary workers - visible again: make it a legitimate and respectable topic of study". This is also because, one might add, just as organization studies have found in STS a new conceptual apparatus with which to read phenomena related to work and organizational processes, so STS may find in contemporary studies on work and organizational practices stimuli and suggestions with which to enrich and renew their interpretative instruments.

It is well known, however (and emphasised on several occasions in the book) that Star regarded the relationship between the visible and invisible as only a starting point from which to address broader issues and dynamics involved in the construction of borders, margins, differences and inequalities. The definition of categories is a political issue, especially in a world where knowledge is increasingly shared among humans, machines and classification standards. As well as in Star's writings, clear evidence of this process is provided in the book's chapters by Gail Hornstein (chapter 14) and Jutta Weber and Cheris Kramarae (chapter 15). Although they deal with very different research objects (respectively, the construction and role of categories in psychiatry, and the categorization of 'civilians' and 'victims' in the war currently being waged in Pakistan by the United States), both contributions testify to the inspirational impact of Star's ideas. They do so in line with the interactionist and 'grounded' approach to the development of sensitizing concepts, able to stimulate the imagination and creativity of the researchers who want to engage with them.

As transpires from several of Star's writings (my favourite has always been, and remains so upon re-reading it, "Living Grounded Theory: cognitive and emotional forms of pragmatism" - chapter 5), her relationship with concepts and ideas was physical, corporeal, and embodied. This brings us to the third great current theme anticipated by Star: affect.

As pointed out by Adele Clarke on discussing different forms of anticipation work (chapter 4: 105), perhaps it was no accident that, as president of 4S, Leigh chose the theme of "Silence, Suffering and Survival" for the annual meeting of the
Society. We must therefore bear in mind that Star's vocabulary consisted not only of concepts such as boundary object, infrastructure, and in/ visible work, but also of truth, spirituality and hope. These concepts are not to be interpreted in 'modern' terms but rather in their post-structuralist sense as spaces-between, occasions that prevent a priori definition of being and the development of events, and interactions. These are concepts which, as noted by Maria Puig de la Bellacasa (in a chapter that I found so beautiful and inspiring that I wish I had written it myself), perfectly matches the ecological formulation of Star's thought. "An ecology (...) evokes a site of intensities, synergies, and symbiotic processes within relational compounds. Ecological circulation functions in cyclic interdependent ways rather than by extension. (...) Ecological thinking is attentive to the capacity of relation-creation, to how different beings affect each other, to what they do to each other, the internal 'poiesis' of a particular configuration." (chapter 2: 53).

Also the famous cui bono? underpinning Star's work since publication of Ecologies of Knowledge (here rightly re-proposed as the book's opening chapter) is a question that does not have the ambition to balance the benefits that some can draw from situations at the expense of others, but to make visible what is hidden, repressed or silenced. Reality is not a zero-sum game. Hence, instead of trying to establish equivalences, it may be more sensible (especially from a pragmatic point of view) to state differences and incommensurabilities.

In conclusion, I believe the book succeeds in the difficult task of paying homage to Star's thought and person, outlining various lenses through which to read her work. For my part, I hope that I have kept the promise made at the beginning of this review and been able to arouse the reader's curiosity in this book, which I believe will give much pleasure to both those who already know Leigh Star and those who have not had the fortune of meeting her work. And if I have dwelt too long on Leigh Star and the cultural (even before theoretical or empirical) contribution made by her work, I apologize, but it is due to a question of affect. 